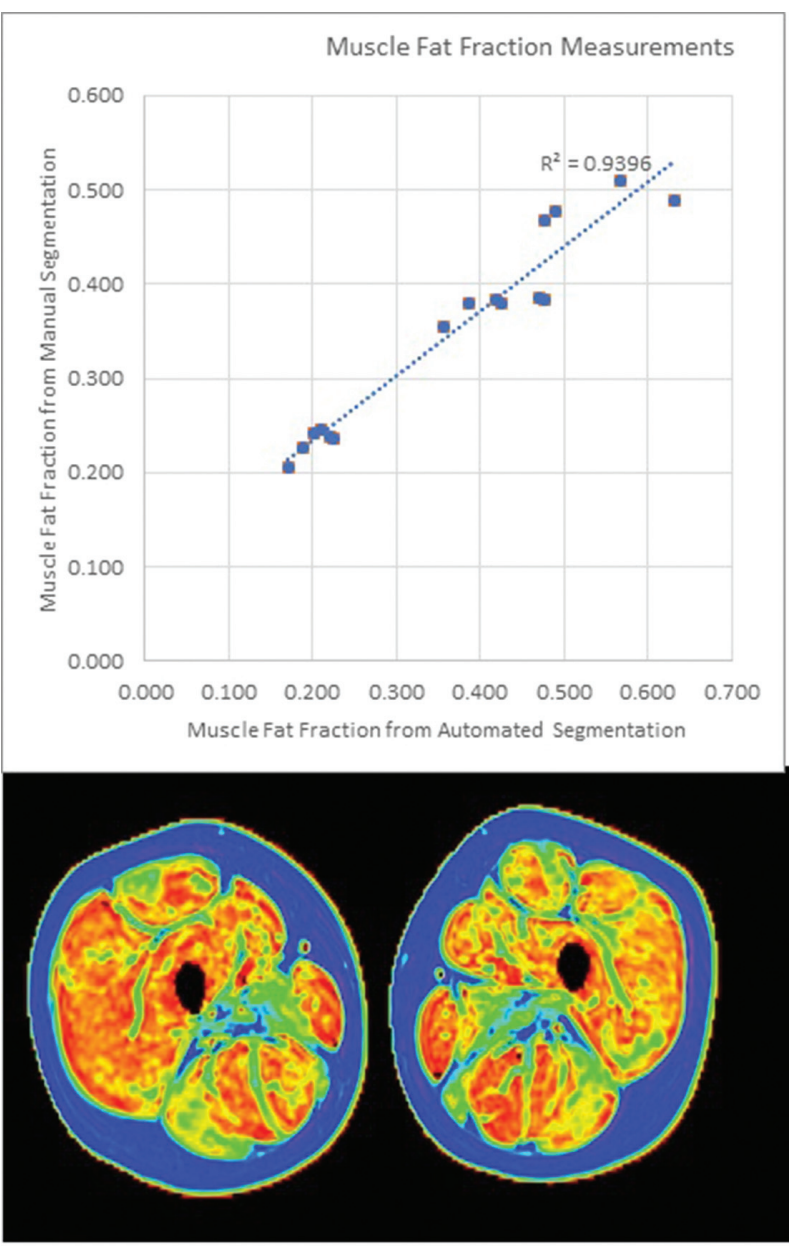

Example Fat Fracton Map

Abstract FRI0582 - Figure 1. Example Fat Fracton Map

Conclusions: In the present study, we reported a segmentation framework based on unsupervised k-means to measure muscle volume and fat fraction. It offers time savings versus manual segmentations and correlates well with fat fraction measurements. This could be useful for muscle quantification in the fields of osteoarthritis, sports medicine and rehabilitation. Further studies are planned to compare sensitivity of automatically acquired measures to clinical progression. Acknowledgements: 1. Amato AA et al. Neurology. 2014 83( 24:2239-46.

2. Beattie, K., Davison, M.J., Noseworthy, M. et al. Rheumatol Int (2016) 36: 855. https://doi.org/10.1007/s00296-016-3455-x

Disclosure of Interest: None declared

DOI: 10.1136/annrheumdis-2018-eular.5108

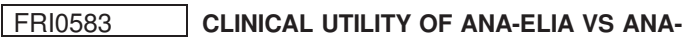 IMMUNOFLUORESCENCE IN CONNECTIVE TISSUE DISEASE}

O. Alsaed ${ }^{1}$, L. Alamilah ${ }^{1}$, O. Al-Radideh², M. Elkhalifa ${ }^{3}$, A.-W. Al-Allaf ${ }^{1} .{ }^{1}$ Medicine/ Rheumatology, ${ }^{2}$ Internal Medicine; ${ }^{3}$ laboratory medicine and pathology, Hamad Medical corporation, Doha, Qatar

Background: Antinuclear antibody (ANA) detection by indirect immunofluorescence technique (ANA-IIF) is the standard test for connective tissue disease (CTD) screening for last 5 decades, which has low specificity and it is labour intensive. ANA detection by fluoroenzyme immunoassay (ANA-Elia) has been developed recently as an alternative method to include 17 ANA-targeted recombinant antigens.
Objectives: Compare the sensitivity and specificity of the new ANA-Elia with conventional ANA-IIF.

Methods: Randomly selected 1458 patient's sera from primary and secondary health care were tested for both the standard ANA-IIF (Diasorin S.P.A, saluggia, Italy) and the new ANA-Elia (Phadia GMbH, Ferieiburg, Germany). ANA-Elia is fluoroenzyme immunoassay performed on the Phadia-250 automated platform. It contains 17 ANA-targeted recombinant antigens; dsDNA, Sm-D, Rib-P, PCNA, U1-RNP (70, A, C), SS-A/Ro (52 and 60), SS-B/La, Centromere B, Scl-70, Fibrillarin, RNA Polymerase III, Jo-1, Mi-2, and PMscl. Result with ratio >1.0 considered positive for the new technique. For ANA-IIF our lab cut off for positive test is $\geq 1: 80$. Patients were evaluated in our rheumatology clinic for fulfilling the correspondent international clinical criteria for various connective tissue diseases.

Results: $75.7 \%$ were females with mean age of $43 \pm 13$ years. 201 (11.5\%) patients confirmed to have clinical CTD as follow: 142 SLE, 24 Sjogren's syndrome, 15 scleroderma, $7 \mathrm{MCT}, 10$ Myositis and 10 undifferentiated CTD. The specificity of ANA-Elia at cut off ratio of $>1$ and ANA-IIF at titer of $\geq 1: 80$ was almost equal, $88.5 \%$ and $87.6 \%$ respectively. However, ANA-Elia has higher sensitivity (74.5\%) as compared to ANA-IIF (61.6\%). At a higher cut off ratio of $>2$ and titer of $\geq 1: 160$, the specificity improved to $93.6 \%-92.6 \%$ respectively.

\begin{tabular}{|c|c|c|c|c|}
\hline & \multicolumn{2}{|c|}{ ANA-Elia } & \multicolumn{2}{|c|}{ ANA-IIF } \\
\hline & $>1$ & $>2$ & $\geq 1: 80$ & $\geq 1: 160$ \\
\hline Sensitivity & $74.5 \%$ & $67.6 \%$ & $61.6 \%$ & $50.7 \%$ \\
\hline Specificity & $88.5 \%$ & $93.6 \%$ & $87.6 \%$ & $92.6 \%$ \\
\hline
\end{tabular}

Conclusions: The ANA testing with the newly developed, use friendly, fully automated and less labour intense method of ANA-Elia can replace the standard conventional ANA-IIF with better specificity.

Disclosure of Interest: None declared

DOI: 10.1136/annrheumdis-2018-eular.5705

\section{FRI0584 FLUORESCENCE OPTICAL IMAGINGENHANCEMENT IS ASSOCIATED WITH JOINT PAIN IN HAND OSTEOARTHRITIS}

$\varnothing_{\text {. Maugesten }}^{1}$, S. Ohrndorf ${ }^{2}$, S.V. Hestetun ${ }^{1}$, B. Slatkowsky-Christensen ${ }^{1}$, T. K. Kvien', T. Uhlig ${ }^{1}$, I.K. Haugen ${ }^{1} .{ }^{1}$ Department of Rheumatology, Diakonhjemmet Hospital, Oslo, Norway; ${ }^{2}$ Dept. of Rheumatology and Clinical Immunology, Charité Univ.smedizin, Berlin, Germany

Background: Joint inflammation plays a role in the pathogenesis of hand osteoarthritis (OA), and previous studies have presented an association between pain and synovitis detected by MRI and ultrasound. No previous hand OA studies have explored the validity of fluorescence optical imaging (FOI), a novel imaging technique demonstrating altered microcirculation in wrist and finger joints, as a sign of inflammation.

Objectives: The aims of the current study were to quantify the distribution of FOIfindings in different joint groups in hand OA patients and explore the association between FOI findings and self-reported pain and tender joints on clinical examination.

Methods: The NOR-HAND study is an observational hand OA study, in which 251 patients ( $88 \%$ female, median age 61 (interquartile range 56-66) years) underwent FOI of both hands, bilateral clinical examination for tender joints on palpation and movement, and self-reported their pain in individual joints during the last 24 hours and the last 6 weeks on the homunculus. The FOl-scan was performed after the administration of an intravenous fluorescence dye (indocyanine green, ICG) and 360 images (1/second) were produced in 6 min. Based on the inflow and washing out of the dye the pictures were divided into 3 phases. Ultimately, the prima vista mode (PVM) represented a composite picture of the first 240 images of the examination. For each phase, fluorescence enhancement in the joints was graded from 0-3 based on signal intensity (grade 1=diffuse red, grade $2=$ intense red and diffuse white $<50 \%$ of the joint, grade $3=$ intense white $>50 \%$ of the joint). To study the association between FOI findings and pain in the same joint we applied logistic regression analyses with generalised estimating equations adjusting for age and sex. Separate models were applied for each of the FOI phases and pain outcomes.

Results: The median (interquartile range) number of DIP/PIP joints with FOI enhancement within each patient ranged from $0(0-0)$ in phase $1,14^{11-16}$ in phase $2,3(0-8)$ in phase 3 and $9^{7-11}$ in PVM. CMC-1 and MCP-joints showed no and uncommon enhancement on the examination, respectively, regardless of the phase, and the associations between $\mathrm{FOI}$ and pain were therefore analysed in the DIP and PIP joints only. FOI enhancement in the DIP and PIP joints was associated with pain in the same joint, consistent for all three pain outcomes. A dose- 
response relationship was found for phase 2, phase 3 and PVM, but not in phase 1 (table 1). Few joints showed enhancement in phase 1 and a clear doseresponse relationship was found for pain during the last 24 hours only (data not shown).

\begin{tabular}{|c|c|c|c|}
\hline \multirow{2}{*}{\multicolumn{4}{|c|}{$\begin{array}{l}\text { Associations between FOI Enhancement } \\
\text { and Pain in the same DIP and PIP Joints. }\end{array}$}} \\
\hline & & & \\
\hline & $\begin{array}{l}\text { Self-reported } \\
\text { pain last } 24 \\
\text { hours }\end{array}$ & $\begin{array}{l}\text { Self-reported } \\
\text { pain last } 6 \\
\text { weeks }\end{array}$ & $\begin{array}{l}\text { Tender joint } \\
\text { on clinical } \\
\text { exam }\end{array}$ \\
\hline & OR $(95 \% \mathrm{CI})$ & OR $(95 \% \mathrm{Cl})$ & OR $(95 \% \mathrm{Cl})$ \\
\hline \multicolumn{4}{|c|}{ FOI phase 1} \\
\hline Grade 0 & 1.00 (ref.) & 1.00 (ref.) & 1.00 (ref.) \\
\hline Grade 1-3 & $\begin{array}{l}1.50(0.94 \\
2.40) \\
\end{array}$ & \begin{tabular}{|l|}
$1.92(1.20$ \\
$3.09)$ \\
\end{tabular} & \begin{tabular}{|l|}
$2.42(1.37$ \\
$4.25)$ \\
\end{tabular} \\
\hline \multicolumn{4}{|c|}{ FOI phase 2} \\
\hline Grade 0 & 1.00 (ref.) & 1.00 (ref.) & 1.00 (ref.) \\
\hline Grade 1 & $\begin{array}{l}1.26 \text { (1.02, } \\
1.55)\end{array}$ & $\begin{array}{l}1.15(0.93, \\
1.44)\end{array}$ & $\begin{array}{l}2.15 \text { (1.81, } \\
2.55)\end{array}$ \\
\hline Grade 2 & $\begin{array}{l}1.94(1.58 \\
2.38)\end{array}$ & $\begin{array}{l}1.92(1.52, \\
2.41)\end{array}$ & $\begin{array}{l}2.69(2.21, \\
3.26)\end{array}$ \\
\hline Grade 3 & $\begin{array}{l}2.25 \text { (1.61, } \\
3.15)\end{array}$ & $\begin{array}{l}2.53(1.73, \\
3.69)\end{array}$ & $\begin{array}{l}4.00(2.85, \\
5.59)\end{array}$ \\
\hline \multicolumn{4}{|c|}{ FOI phase 3} \\
\hline Grade 0 & 1.00 (ref.) & 1.00 (ref.) & 1.00 (ref.) \\
\hline Grade 1 & $\begin{array}{l}1.76(1.42 \\
2.17)\end{array}$ & $\begin{array}{l}1.73(1.40 \\
2.14)\end{array}$ & $\begin{array}{l}2.15(1.77 \\
2.61)\end{array}$ \\
\hline Grade $2+3 *$ & $\begin{array}{l}2.29(1.30 \\
4.06) \\
\end{array}$ & $\begin{array}{l}2.51(1.33 \\
4.73) \\
\end{array}$ & $\begin{array}{l}3.21(1.91 \\
5.39) \\
\end{array}$ \\
\hline \multicolumn{4}{|c|}{ FOI Prima Vista Mode } \\
\hline Grade 0 & 1.00 (ref.) & 1.00 (ref.) & 1.00 (ref.) \\
\hline Grade 1 & $\begin{array}{l}1.36 \text { (1.14, } \\
1.61)\end{array}$ & $\begin{array}{l}1.38 \\
(1.14,1.68)\end{array}$ & $\begin{array}{l}2.20(1.88, \\
2.56)\end{array}$ \\
\hline Grade 2** & \begin{tabular}{|l|}
$2.37(1.88$ \\
$2.98)$ \\
\end{tabular} & \begin{tabular}{|l|}
$2.33(1.81$ \\
$3.00)$ \\
\end{tabular} & $\begin{array}{l}3.22(2.57 \\
4.04) \\
\end{array}$ \\
\hline \multicolumn{4}{|c|}{$\begin{array}{l}\text { * Grades } 2 \text { and } 3 \text { combined due to few joints with } \\
\text { grade } 3 \text { in phase } 3 .{ }^{* *} \text { No joints with grade } 3 \text { in prima } \\
\text { vista mode (PVM). }\end{array}$} \\
\hline
\end{tabular}

Conclusions: In this first hand OA study, FOI enhancement was frequently found in the DIP and PIP joints, whereas the method seems insensitive to detect inflammation in the CMC-1 joints. FOI enhancement was related to self-reported pain and to tender joints on clinical examination, supporting the validity of the FOI examination in patients with hand $O A$.

Disclosure of Interest: None declared

DOI: 10.1136/annrheumdis-2018-eular.4735

\section{FRI0585 PREVALENCE OF ANTI-ACETYLATED PROTEIN ANTIBODIES IN INFLAMMATORY ARTHRITIS, OSTEOARTHRITIS, CONNECTIVE TISSUE DISEASES AND ITS DISCRIMINATIVE CAPACITY AS DIAGNOSTIC MARKER FOR EARLY RHEUMATOID ARTHRITIS}

P. Studenic ${ }^{1}$, H. Bang ${ }^{2}$, A. Alunno ${ }^{3}$, D. Sieghart ${ }^{1}$, D. Aletaha ${ }^{1}$, S. Blüml ${ }^{1}$, H. Haslacher ${ }^{4}$, J.S. Smolen ${ }^{1}$, G. Steiner ${ }^{1}{ }^{1}$ Internal Medicine 3, Division Of Rheumatology, Medical University Vienna, Vienna, Austria; ${ }^{2}$ Orgentec Diagnostika GmbH, Mainz, Germany; ${ }^{3}$ Rheumatology Unit, Department of Medicine, University of Perugia, Perugia, Italy, ${ }^{4}$ Department of Laboratory Medicine, Medical University Vienna, Vienna, Austria

Background: Numerous post-translationally modified proteins have been described as auto-antigens in rheumatoid arthritis (RA) patients. Antibodies (abs) against acetlyated (ac) peptides (AAPA) have recently been reported in RA patients, but not yet been evaluated in other inflammatory and non-inflammatory rheumatologic conditions; therefore their specificity (spec) and sensitivity (sens) remains unclear.

Objectives: To determine the prevalence of AAPA in RA, healthy subjects and other rheumatic diseases in order to evaluate their diagnostic potential for discriminating RA, healthy and other rheumatic diseases.

Methods: We obtained serum samples of patients with early untreated RA, established RA ( $>3$ years), osteoarthrits (OA), systemic lupus erythematosus, granulomatosis with polyangiitis (GPA), polymyositis, axial spondyloarthritis, primary Sjögren's syndrome and healthy subjects. AAPA were measured by ELISA using peptides derived from mutated vimentin (acetylation of lysine or ornithine in position 7 or 2 (inverse peptide), as antigen. Receiver operating characteristics and logistic regression analyses were used to assess the discriminative capacity of AAPA.

Results: Areas under the curves (AUC) were significant in early RA (eRA; $n=120$; $75 \%$ female, mean disease duration: $-0.07+0.51$ years, mean symptom duration $1.49 \pm 2.01$ years) versus healthy subjects for IgG-abs against ac lysine, inverse lysine and ornithine (AUC of $0.666,0.687,0.800$, respectively). We chose a cutoff of $20 \mathrm{U} / \mathrm{ml}$ putting an emphasise on high spec, with balanced sens (ac-lysine: spec: 97.0\%; sens: 32.5\%;+likelihood ratio (LR) 10.7, Cl: 3.4-33.7; ac-inverselysine: spec: $80.7 \%$; sens: 42\%;+LR 2.2, Cl: 1.3-3.6; ac-ornithine: spec: $93.9 \%$; sens: $39.2 \% ;+$ LR $6.5 ; \mathrm{Cl}: 2.9-14.5)$. Analyses of positivity for multiple ab-reactivity revealed increasing + LR by number of abs, with $100 \%$ specifity when all 3 AAPAs are detected (table 1). Testing this cutoff against OA patients showed similar specificities, but with lower +LR (2 AAPA:+LR 3.48, Cl: 1.9-6.6). Sens is increased when testing established RA versus healthy controls, with ac-ornithine performing best (ac-lysine: 49.2\%, Cl: 42.0-56.5; ac-inv-lysine: 35.2\%, Cl: 28.5-42.4; acornithin: $53.9 \%, \mathrm{Cl}: 46.6-61.0)$

We found that practically only RA patients showed three different AAPA reactivities (in eRA: $39 \%$ positive for ac-ornithine abs, 33\% for ac-lysine abs, $48 \%$ for inverse ac-lysine abs). Polymyositis and GPA patients showed the lowest prevalence of AAPA (Graph 1A).

Among eRA patients $17 \%$ were found to be exclusively positive for AAPA, while $39 \%$ were also positive for rheumatoid factor (RF) and anti-citrullinated antibodies (ACPA) (distribution in Graph 1B). Also in RF- and ACPA- patients the presence of one AAPA identified RA patients vs. healthy subjects with a spec of $77.7 \%$ and those with 2 AAPA reactivities with even $97 \%$ respectively.

Abstract FRI0585 - Table 1. Sensitivity, specificity, positive and negative likelihood ratio (LR) for identifying early RA patients against healthy controls by the number of AAPA reactivities

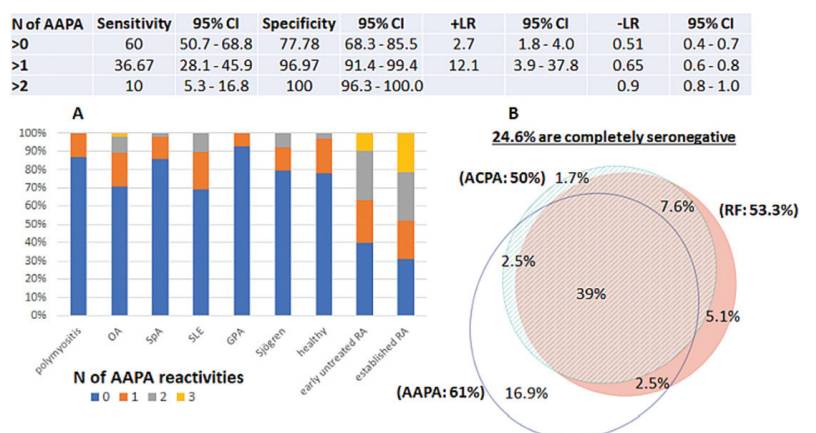

Graph 1A: Prevalence (in\%) of IgG antibodies against the 3 different acetylated peptides using $20 \mathrm{U} / \mathrm{ml}$ as cutoff

Graph 1B: Venn diagram, outlining the distribution and overlap of AAPA (blue circle), ACPA (striped circle) and RF (rose circle) in early rheumatoid arthritis patients $(n=120)$

Conclusions: AAPA are highly prevalent autoantibodies in early RA, closing a further gap of seronegativity, with only $24.6 \%$ of early RA patients remaining negative for RF, ACPA or AAPA. In particular, multiple reactivity to AAPA increased the specificity for eRA, also adding diagnostic value beyond RF and ACPA.

Disclosure of Interest: P. Studenic: None declared, H. Bang Employee of: Orgentc Diagnostika $\mathrm{GmbH}$, A. Alunno: None declared, D. Sieghart: None declared, D. Aletaha: None declared, S. Blüml: None declared, H. Haslacher: None declared, J. Smolen: None declared, G. Steiner: None declared DOI: 10.1136/annrheumdis-2018-eular.3945 